\title{
Adjuvant effects on the retention and uptake of spirotetramat insecticide sprays on kiwifruit
}

\author{
R.E. Gaskin ${ }^{1}$, D.B. Horgan ${ }^{1}$, R.M. van Leeuwen ${ }^{1}$ and D.W. Manktelow ${ }^{2}$ \\ ${ }^{1}$ Plant Protection Chemistry ${ }_{N Z}$ P O Box 6282, Rotorua 3043, New Zealand \\ ${ }^{2}$ Applied Research and Technologies Ltd, PO Box 3415, Napier, New Zealand \\ Corresponding author: robyn.gaskin@ppcnz.co.nz
}

\begin{abstract}
Spirotetramat $\left(\right.$ Movento $^{\circledR}$ ) is a systemic insecticide that can control scale insects on kiwifruit. It must be tank-mixed with a spray adjuvant to maximise leaf uptake. This study investigated how two adjuvants, a penetrating oil and a superspreader, affected spray retention and uptake of spirotetramat into kiwifruit leaves, from dilute and concentrated spray mixes. Spray retention and distribution of airblast-applied, high volume, dilute sprays containing the oil adjuvant were good, but retention was reduced when sprays were concentrated. Concentrated sprays, containing the superspreader adjuvant, were retained and distributed similarly to the dilute sprays containing oil adjuvant. Spirotetramat uptake into foliage was generally low, but was greater with the oil penetrant than with the superspreader. Concentrating sprays and increasing adjuvant concentrations could increase insecticide uptake, as could combining the two adjuvants together in a spray. The potential of the adjuvants to maximise spirotetramat efficacy in concentrate sprays and to reduce residues at harvest is discussed.
\end{abstract}

Keywords esterified seed oil adjuvant, superspreader adjuvant, concentrate sprays, spray deposits, Diaspididae, Actinidia chinensis.

\section{INTRODUCTION}

The control of scale insects (Hemiptera: Diaspididae) on kiwifruit (Actinidia chinensis) is difficult because scale inhabit sites not easily accessed by sprays (Hill et al. 2006). Scale is a quarantine and cosmetic pest and if not controlled, causes market access problems for kiwifruit exports. Most insecticides can only be applied pre-flowering because of their long residual life. The detection of insecticide residues in export fruit also affects market access.

Spirotetramat (240 g/litre, SC, Movento ${ }^{\circledR}$, Bayer) is an innovative new insecticide used to control scale insects. It distributes via the phloem and xylem in plants, to eliminate sucking insect pests (Brück et al. 2009). It controls cryptic pests and protects new shoots emerging after foliar application. Bayer advises reduced spray application volumes can be used due to the highly systemic nature of the product, but SC formulations must be tank-mixed with a spray adjuvant having spreading and penetration properties to exploit the full biological efficacy. Recommended adjuvants include methylated seed oils or organosilicone surfactants, depending on the crop (Bayer 2009). 
The studies reported here were undertaken to determine how two adjuvants with different modes of action, an esterified seed oil penetrant and an organosilicone blend superspreader, affected spray retention, coverage and uptake of spirotetramat into kiwifruit leaves, with dilute and concentrated spray mixes. These studies contribute to a project aiming to achieve nil detectable residues in fruit at harvest while maximising the efficiency of scale control on kiwifruit.

\section{METHODS AND MATERIALS}

\section{Field deposit study}

The study was conducted in November 2009 on commercial 'Hayward' kiwifruit vines, trained on a pergola system with row spacing of $5 \mathrm{~m}$. The orchard was sited in Williams Road, Tauranga, and was surrounded by shelterbelts on all sides All treatments were applied on the same day; mean wind speeds varied up to $1.1 \mathrm{~m} / \mathrm{s}$ and were typical of normal spraying conditions. Each treatment was applied to a randomly allocated plot in each of two physically separated blocks within the same orchard. Each plot consisted of three bays within a row (ca $24 \mathrm{~m}$ long plots). There were buffers of at least one complete bay between plots, and one row between each treatment row. Sprays were applied to two adjacent rows in each treatment. Treatments were applied using an industry standard, trailed, Fantini airblast sprayer, with a front entry $800 \mathrm{~mm}$ axial fan producing ca $30,000 \mathrm{~m}^{3} / \mathrm{h}$ air output. Treatments were applied at $5.2 \mathrm{~km} / \mathrm{h}$, with the sprayer fitted with disc and core cone nozzles at pressures between 1800 and $2400 \mathrm{kPa}$ (wide angle cones directed spray to the canopy above the sprayer, with progressively narrower angle nozzles used to direct spray towards the vine leaders). Treatments were applied either as dilute (2000 litres/ha), $2 \times$ concentrate (1000 litres/ha) or $3 \times$ concentrate (700 litres/ha) sprays. Large droplet air inclusion (AI) nozzles were used in two low volume ( $3 \times$ concentrate) treatments. These nozzles are typical of the industry standard setup for the low drift application of dormancy breaking sprays. These treatments were included to determine whether there was potential to use this setup for an in-season low volume application.

All treatments (Table 1) contained Calcium 175 (175 g/litre elemental calcium, GroChem) applied at 10 litres/ha as a tracer to quantify spray deposits. Two adjuvants were used:Partner ${ }^{\circledR}$ (ESO, $70 \%$ esterified canola seed oil, Bayer CropScience) and Du-Wett ${ }^{\circledR}$ (DW, organosilicone/ organic fluid blend, Elliott Technologies Ltd). Movento ${ }^{\circledR}$ was not included in sprays as it had no effect on the physical properties of the spray solutions (data not presented). Samples were collected from the central bay of each sample plot immediately after spray had dried and washed on site within $15 \mathrm{~min}$ of harvest. Foliage was sampled from three zones in the pergola canopy: centre of bay, at the leader vine and mid-way between the two. Four replicates (consisting of five randomly picked leaves) were sampled from each canopy zone: two from the lower canopy position (exposed directly to the sprayer) and two from the upper (sheltered from direct spray by lower foliage). Samples of all treatment solutions were taken from the spray tank immediately after each application.

Foliage samples were washed in distilled water $(200 \mathrm{ml})$ and solutions measured immediately with a portable ion conductivity meter (Russell RL060C) to quantify calcium ion recovery. Leaf areas were subsequently measured with a Li-Cor 3100 leaf area meter. Calcium deposits were calculated as dose $\left(\mu \mathrm{g} / \mathrm{cm}^{2}\right.$ of leaf). These results were standardised against the known calcium application rate (calculated from the tank concentration and measured sprayer output for each treatment) and results were normalised at $1 \mathrm{~kg} / \mathrm{ha}$ calcium application to enable comparison of treatments. Results were statistically analysed using analysis of variance (Statistix 9) to determine the significance of treatment on spray deposits and their distribution within the canopy.

\section{Uptake study}

'Haywood' kiwifruit plants (approximately $1.5 \mathrm{~m}$ tall) were potted up in winter and maintained outdoors until used in spring through summer. Plants were transferred to a controlled 
environment (CE) at least 1 week prior to any experiment and maintained at $20^{\circ} / 15^{\circ} \mathrm{C}$ day/ night temp, $70 \% \mathrm{RH}$ and $14 \mathrm{~h}$ photoperiod of approx $500 \mu \mathrm{mol} / \mathrm{m}^{2} / \mathrm{sec}$. Foliage was well washed with water spray prior to moving into the CE. Spirotetramat $\left({ }^{14} \mathrm{C}\right.$-radiolabel specific activity 3.67 MBq/mg, incorporated in Movento ${ }^{\circledR}$ SC formulation at $17.4 \mathrm{MBq} / \mathrm{ml}, 240 \mathrm{~g} /$ litre ai, Bayer CropScience) was used at the recommended rate throughout (96 g ai/ha). Treatments (Table 2) were applied by dispensing droplets $(20 \times 0.24$ $\mu \mathrm{l})$ with a repeating microsyringe to adaxial and abaxial leaf surfaces. Droplet density on leaves was varied to simulate appropriate spray application volumes (Table 2). The uptake of spirotetramat (96 g/2000 litres/ha) without adjuvant addition was also determined. Spread areas were determined on both leaf surfaces (Gaskin \& Pathan 2008). Treatments were replicated on five separate plants. Uptake was determined at $24 \mathrm{~h}$ after treatment. Surface washes of application sites, to recover unabsorbed insecticide, were made with $4 \times 4 \mathrm{ml}$ of acetone+water $(1+1 \mathrm{v} / \mathrm{v})$, then diluted with scintillant solution (ACS, Amersham Biosciences) and radioactivity was quantified using a liquid scintillation counter
(Packard TriCarb 2100TR). At harvest, any signs of phytotoxicity (visible damage to the leaf surface at the site of treatment application) were noted. Foliar uptake was defined as radiolabel not recovered by washes and was calculated as a percentage of the applied amount. Treatments were compared using analysis of variance (Statistix 9) and least significant difference (LSD) tests. Variance stabilising transformations were made where necessary prior to analysis.

\section{RESULTS}

Spray retention and canopy zone distribution of the standard, dilute spray (2000 litres/ha) and the $2 \times$ concentrate spray containing the oil adjuvant (ESO) was good (Table 1), but was reduced when the spray was concentrated $3 \times$. Concentrated sprays $(2 \times$ and $3 \times)$, containing the lowest concentration of the superspreader adjuvant (DW), were retained and distributed similarly to the standard dilute spray, but increasing the adjuvant concentration generally decreased deposits in all canopy zones (Table 1). This may be indicative of over-wetting and loss of spray to run-off. The mid canopy zone, closest to the spray nozzles, was targeted best overall

Table 1 Deposits ( $\mu \mathrm{g} / \mathrm{cm}^{2}$, normalised to a $1 \mathrm{~kg} / \mathrm{ha}$ application of calcium) on kiwifruit foliage in three canopy zones, from sprays applied with varying nozzles, spray volumes and adjuvants.

\begin{tabular}{|c|c|c|c|c|c|c|}
\hline \multirow{2}{*}{$\begin{array}{l}\text { Spray volume } \\
\text { (litres/ha) }\end{array}$} & \multirow[b]{2}{*}{ Adjuvant } & \multirow{2}{*}{$\begin{array}{c}\text { Adjuvant conc. } \\
(\%)\end{array}$} & \multicolumn{3}{|c|}{ Canopy zone } & \multirow{2}{*}{$\begin{array}{c}\text { Treatment } \\
\text { mean }^{1}\end{array}$} \\
\hline & & & centre & mid & leader & \\
\hline 2000 & ESO & 0.10 & 3.57 & 4.96 & 3.61 & $4.05 \mathrm{ab}$ \\
\hline 1000 & ESO & 0.20 & 4.34 & 4.36 & 4.26 & $4.32 \mathrm{a}$ \\
\hline 700 & ESO & 0.29 & 2.89 & 3.59 & 3.18 & $3.22 \mathrm{~cd}$ \\
\hline 1000 & DW & 0.025 & 4.89 & 3.96 & 4.14 & $4.33 \mathrm{a}$ \\
\hline 1000 & DW & 0.05 & 4.10 & 2.85 & 2.57 & $3.17 \mathrm{~cd}$ \\
\hline 700 & DW & 0.025 & 3.72 & 4.42 & 3.56 & $3.90 \mathrm{abc}$ \\
\hline 700 & DW & 0.05 & 2.72 & 3.91 & 3.21 & $3.30 \mathrm{bcd}$ \\
\hline $700 \mathrm{AI}$ & DW & 0.05 & 3.08 & 3.83 & 1.93 & $2.95 \mathrm{~d}$ \\
\hline 700 & DW & 0.075 & 2.72 & 3.31 & 2.38 & $2.80 \mathrm{~d}$ \\
\hline $700 \mathrm{AI}$ & DW & 0.075 & 3.36 & 3.22 & 2.39 & $2.99 \mathrm{~d}$ \\
\hline \multicolumn{3}{|l|}{$\operatorname{LSD}(\mathrm{P}=0.05)$} & -------- & $-1.34-$ & ----- & \\
\hline \multicolumn{3}{|c|}{ Canopy zone mean ${ }^{1}$} & $3.54 \mathrm{AB}$ & $3.84 \mathrm{~A}$ & $3.12 \mathrm{~B}$ & \\
\hline
\end{tabular}

${ }^{1}$ Means sharing common postscripts are not significantly different (LSD, $\mathrm{P}=0.05$ ). 
and the leader zone generally received lower deposits (Table 1). This highlights the difficulty of projecting spray droplets $>2 \mathrm{~m}$ to the leader zone, with the lower mass of spray liquid in the low volume, concentrate treatments appearing more vulnerable to wind or other disruption. The two concentrate treatments replicated with AI nozzles were generally equivalent to the hollow cone applications at the same application volume with the same adjuvant concentrations, but the fall-off in deposit levels seen in the leader zone of one AI treatment (Table 1) and in the shielded, upper canopy foliage of both AI treatments (50\%, data not presented) was of concern. These nozzles are probably not suitable for use in leafy kiwifruit canopies. Over all treatments, the foliage in the lower, exposed canopy position received approximately 40\% higher deposits than the shielded, upper foliage $(\mathrm{P}<0.001$, data not presented). These deposit profiles were as expected from airblast spray applications to pergola trained kiwifruit.

A comprehensive series of uptake experiments (not all data are presented here) established the effects of ESO and DW adjuvants on spirotetramat absorption into kiwifruit leaves. Uptake was often similar from both leaf surfaces (Table 2) and where it was not, then the lower surface generally absorbed less spirotetramat. Without adjuvant, the uptake of spirotetramat from dilute (2000 litres/ha) spray by both surfaces was negligible, at ca 3\%. The ESO, at the recommended addition of 2 litres/ha, increased mean uptake to $21 \%$ (Table 2). Uptake of spirotetramat into kiwifruit leaves was generally low; it was greater with the penetrating adjuvant (ESO, 0.7-2 litres/ha) than with the superspreader (DW, 0.2-1 litre/ha), but never exceeded $30 \%$ and $15 \%$, respectively (Figure 1). Increasing the concentration of ESO in the $3 \times$ concentrate spray increased uptake slightly $(\mathrm{P}<0.05$, Figure 1a) and concentrating spirotetramat in sprays containing ESO improved abaxial surface uptake in particular (Table 2). Increasing the concentration of DW in the $3 \times$ concentrate spray increased uptake markedly $(\mathrm{P}<0.001$, Figure $1 \mathrm{~b})$, whereas concentrating the insecticide in DW sprays had no effect on uptake (Table 2).

The ESO spray droplets spread very little and concentration of ESO had no effect on droplet spread (Table 2). DW superspreading was positively correlated with its concentration and its spread was many times greater than ESO. Movento ${ }^{\circledR}$ concentration had no effect on DW superspreading properties and droplet spreading was always greater on the easy-to-wet adaxial than on the difficult-to-wet abaxial leaf surface of kiwifruit.

The uptake study was extended to test the effect of combining the penetrating oil adjuvant

Table 2 Uptake at $24 \mathrm{~h}$ after treatment and surface area $\left(\mathrm{mm}^{2}\right)$ of spirotetramat spray droplets containing ESO or DW adjuvant on upper and lower surfaces of kiwifruit leaves.

\begin{tabular}{|c|c|c|c|c|c|c|c|}
\hline \multirow{2}{*}{$\begin{array}{l}\text { Spray volume } \\
\text { (litres/ha) }\end{array}$} & \multirow[b]{2}{*}{ Adjuvant } & \multirow{2}{*}{$\begin{array}{l}\text { Adjuvant } \\
\text { conc. }(\%)\end{array}$} & \multicolumn{3}{|c|}{ \% Uptake } & \multicolumn{2}{|c|}{ Droplet spreading } \\
\hline & & & adaxial & abaxial & mean & adaxial & abaxial \\
\hline 2000 & ESO & 0.10 & 29 & 14 & 21 & 2.9 & 2.4 \\
\hline 1000 & ESO & 0.20 & 21 & 19 & 20 & 2.7 & 2.3 \\
\hline 700 & ESO & 0.29 & 30 & 24 & 27 & 2.8 & 2.3 \\
\hline 1000 & DW & 0.025 & 3.1 & 0.7 & 1.9 & 5.8 & 3.4 \\
\hline 1000 & DW & 0.05 & 4.4 & 5.3 & 4.9 & 19 & 9.1 \\
\hline 700 & DW & 0.025 & 0.9 & 1.4 & 1.2 & 5.8 & 3.4 \\
\hline 700 & DW & 0.05 & 1.5 & 4.7 & 3.1 & 19 & 9.1 \\
\hline 700 & DW & 0.075 & 3.6 & 2.8 & 3.2 & 28 & 11 \\
\hline \multicolumn{3}{|l|}{$\operatorname{LSD}(\mathrm{P}=0.05)$} & \multicolumn{2}{|c|}{------5.2------ } & 3.6 & \multicolumn{2}{|c|}{------1.73------- } \\
\hline
\end{tabular}


(a)

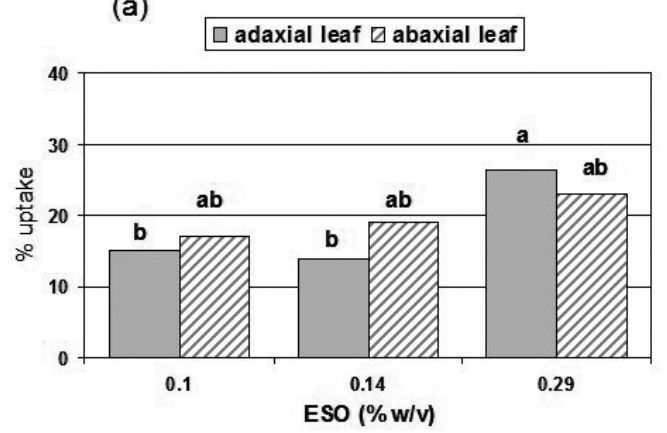

(b)

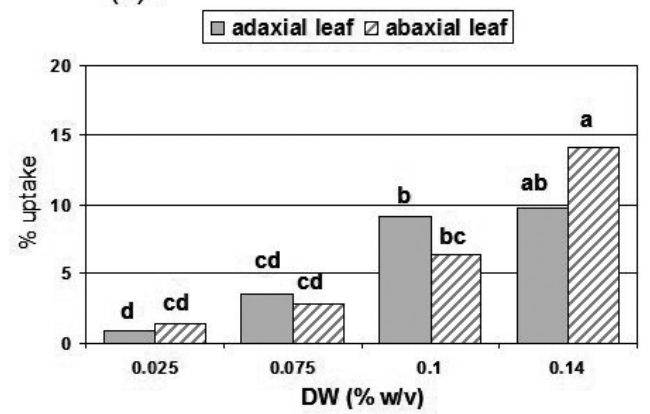

Figure 1 Uptake (\%) of spirotetramat in 700 litres/ha into kiwifruit foliage with varying concentrations of (a) ESO and (b) DW adjuvants. Means sharing common letters are not significantly different $(\mathrm{P}>0.05)$.

(ESO) and the superspreader (DW) together in a concentrate spray of spirotetramat, applied at 700 litres/ha. Increasing the concentration of ESO in a spray containing DW (0.1\%) increased insecticide uptake, primarily on the adaxial leaf surface (Figure 2a). Increasing DW concentration in a spray containing ESO $(0.29 \%)$ had no effect on uptake from the abaxial surface and only increased uptake on the adaxial surface at the highest concentration tested (Figure 2b). Phytotoxicity was observed as leaf browning at the site of droplet application and it increased as ESO concentration increased, indicating increased penetration of sprays. DW concentration had no effect on phytotoxicity.

\section{DISCUSSION}

The deposit and uptake trends in this study demonstrate some important concepts for maximising spirotetramat efficacy and reducing residues. Improving deposits and spray coverage on foliage with adjuvants will not necessarily increase efficacy if they reduce insecticide uptake. If sprays are concentrated more than $2 \times$ with the recommended oil adjuvant then deposits on foliage may be reduced. This may be compensated for by increased uptake from the abaxial surface of leaves, which is the principal target in pergola sprays. This approach is unlikely to reduce residues and may cause phytotoxicity. (a)

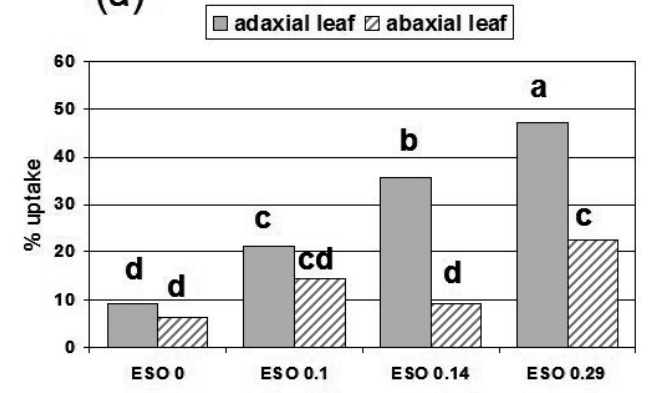

(b)

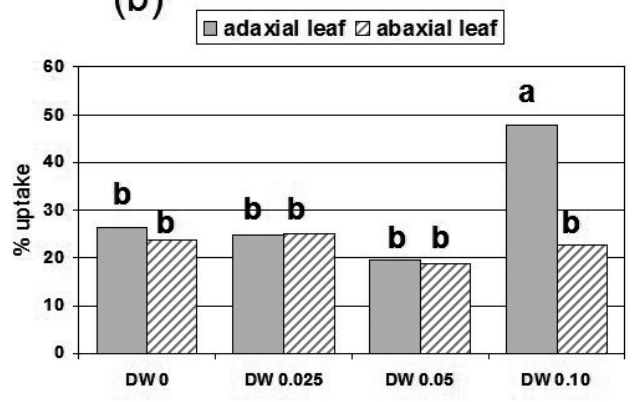

Adjuvant rate $\% \mathrm{w} / \mathrm{v}$

Figure 2 Uptake (\%) of spirotetramat in 700 litres/ha into kiwifruit foliage with (a) DW (0.1\%) + ESO varying concentration and (b) ESO $(0.29 \%)+$ DW varying concentration. Means sharing common letters are not significantly different $(\mathrm{P}>0.05)$. 
Spirotetramat efficacy against scale on citrus is reported to be improved with use of a superspreader adjuvant (Grafton-Cardwell 2009). The use of a low concentration of superspreader adjuvant in concentrated sprays applied to kiwifruit will maintain overall deposits on foliage and markedly increase the area of foliage contacted (covered) by sprays. While uptake of insecticide from a point source on the leaf will be lower than with an oil adjuvant, the superspreader will promote uptake over a larger area of leaf and may provide more widespread control of scale with less chemical dose in the vine. This could potentially reduce residues. Combining the penetrating oil adjuvant and the superspreader in a concentrate spray of spirotetramat has the potential to maximise deposits, coverage and uptake of the insecticide. As a consequence, the amount of chemical required to control scale may be reduced and this may provide the industry with the much needed option of applying insecticides post-blossom without exceeding Maximum Residue Levels. Additionally, the efficacy of post-harvest applications to control sucking insects could be maximised with both adjuvants combined in the spray. Field trials to test these hypotheses are planned.

\section{ACKNOWLEDGEMENTS}

Thanks to R \& R tractors (Te Puke) for providing the tractor and sprayer and to Sophie Hardy for use of her orchard. Bayer CropSciences provided the radiolabelled insecticide and Partner adjuvant. Elliott Technologies Ltd supplied DuWett adjuvant and funded some uptake studies. Gro-Chem NZ Ltd supplied Calcium 125. Bill May (Spray-Tec), Kevin Steele, Alison Forster, Mark Geddes and Justin Nairn (all from $\mathrm{PPC}_{\mathrm{NZ}}$ ) provided technical assistance. Cathy McKenna (Plant \& Food Research) supplied potted kiwifruit plants. Funding was provided by ZESPRI and the MAF Sustainable Farming Fund.

\section{REFERENCES}

Bayer 2009. Movento. www.bayercropscience.co. $n z /$ default.asp?V_DOC_ID $=860$ (accessed 21 May 2010).

Brück E, Elbert A, Fischer R, Kreuger S, Kühnhold J, Kleuken AM, Nauen R, Niebes JF, Reckmann U, Schnorback HJ, Steffens R, Waetermeulen X 2009. Movento ${ }^{\circledR}$, an innovative ambimobile insecticide for sucking insect pest control in agriculture: Biological profile and field performance. Crop Protection 28: 838-844.

Gaskin RE, Pathan AK 2008. Characterising plant surfaces and adjuvant interactions to improve pesticide spray retention and coverage on avocados. NZ Avocado Growers' Assn Annual Research Report 6: 63-69.

Grafton-Cardwell B 2009. Univ. of California. http://westernfarmpress.com/grapes/ insecticide-movento-0216/ (accessed 16 April 2010).

Hill MG, Mauchline NA, Ramankutty P 2006. Armoured scale insect infestation on kiwifruit in relation to position on the vine. New Zealand Plant Protection 59: 47-50. 